\title{
TINKERING TOWARD SUCCESS:
}

\section{Prelude to a Theory of Scientific Practice}

\author{
KARIN D. KNORR
}

Ever since "science" itself became a legitimate object of inquiry, it has been the subject of two all-pervading assumptions:

1) That there is a limited set of characteristics which uniquely define this object; and

2) that this specific reality of science has to do with its peculiar cognitive and theoretical interest in the subject matter from which knowledge is generated.

Epistemology has traditionally taken on the task of justifying this knowledge by attributing to science a specific rationality, most often located in its method of inquiry. ${ }^{1}$ But when this project itself needed justification following a series of challenges to its proposed criteria, ${ }^{2}$ history, sociology and psychology of science were pledged to carry on the struggle. By displaying the historical, social and psychological factors at work in science, recent studies of the area have helped to destroy what Mitroff called the "storybook image" of science. ${ }^{3}$ Since a certain amount of social arbitrariness has thereby been introduced into the notion of scientific enterprise, the question arises as to whether or not the cognitive character so readily attributed to science must remain as a basic presupposition. The logical systems reconstructed by epistemologists, the systems of belief posited by sociologists and historians, and the structures erected by the archaeologists of knowledge all have cognitive objectives. Each assumes that science has to do above all with ideas related through some sort of order. Critical rationalists when studying scientific theories link this order to falsificationism and criteria of cumulative progression; structuralists conceive of those ideas as regulated systems of arbitrary elements; students of Bourdieu postulate quasi-economical calcu- 
lations about investments as ruling an order of ideas left in itself untouched; evolutionists stress the mechanisms of selection and mutation in the progress of ideas; and sceptics emphasize the historically arbitrary character of scientific belief-systems. But what if science (and scientific progress) were never primarily concerned with systems of ideas? ${ }^{4}$

The present paper documents and analyzes the research process on the basis of an observation study done at a large research institution in 1976-77. ${ }^{5}$ As such, it operates in the sphere between "internal" and "external" variables, between reasoning (not rationality!) and interests: the laboratory site. The laboratory site is the cell which breeds the facts and the fields of empirical science, and the collective "faith" which sustains its form of life. Nowhere within this site do we seem to find the worlds of ideas we are looking for, nor the cognitive objects and interests generally identified with research. The laboratory site is a practice. In the following pages, I shall illustrate some aspects of this practice.

\section{Scientific Action: The Predominant Model}

For a study of the research process, the most relevant and influential attempt to develop a notion of scientific action in the natural and technological sciences (in contrast to the social sciences) is found in Habermas' recent writings. Starting from the dichotomy between work (labor) ${ }^{6}$ and the interaction considered fundamental for the reproduction and self-constitution of the human species, Habermas arrives at the juxtaposition of two distinctive types of action, called "instrumental" and "communicative": in the framework of an empirical-analytic inquiry into the natural and technological sciences, reality is objectified through instrumental action from the viewpoint of technical control. The following features seem to constitute instrumental action: ${ }^{7}$

1) Language is no longer embedded in interaction, but attains "monologic closure" in the relationship of a subject (the scientist) confined to an object (nature).

2) Action is severed from communication and reduced to the solitary act of purposeful and rational utilization of means.

3) Theory and experience are divorced; operations of measurement permit a reversible univocal correlation of operatively determined events and systematically connected signs (the theories). 
In contrast to this, the context of communicative action is established by the grammar of language-games which link symbols and expressions (as well as non-verbal actions). Reality is constituted within a framework which is the form of life of communicating groups, organized through ordinary language. Through hermeneutic procedures, schemata of world interpretation are established for which there are no grounds other than further interpretations. ${ }^{8}$ The paradigm of communicative action is the cultural sciences; here the hermeneutic processes of inquiry are linked to an interest in maintaining the intersubjectivity of mutual understanding. Since hermeneutics first arises in "the course of" practical life, where people are dependent upon intercourse with one another, Habermas calls this interest "practical."

The claim that modern natural and technological science presupposes a perspective of technical control cannot be plausibly questioned. In the conduct of inquiry, this means that scientific attributes are constituted with regard to the system of reference of possible instrumentation, and potential operative verification is presupposed in the conception of scientific problems. ${ }^{10}$ However, in the process of blending his discussion of the transcendental framework of modern science with illustrations of actual research procedure, Habermas invests scientific action with properties which are neither necessary for the epistemological argument nor borne out by logical or empirical analysis. "Monologic closure," separation from symbolic interaction and confinement to the correlative systematics of a post hoc relationship between language and experience, all confer a peculiar theoretical character to scientific inquiry and understanding. This theoretical character can be traced back to Heidegger, ${ }^{11}$ who grants the physical sciences a mode of dealing with objects which exempts them from the reflexivity and indexicality of the interpretative mode of understanding present in everyday life as well as in the human science. While Heidegger was probably the first to systematically allude to the human interests underlying the technical nature of the scientific project, scientific activities (as well as scientific objects) remain strangely decontextualized. The theoretical understanding of science is held to neglect (everyday) context in order to assert isolated predicates of isolated objects. ${ }^{12}$ But, while it appears correct to stress that science abstracts from the "referential totality" of our ongoing everyday activities, the referential context which underlies the establishment (in the laboratory) and verification (through our industrial concerns) of scientific predicates cannot be left out of the picture. ${ }^{13}$

Interestingly, the above model of scientific inquiry has been highly influential in shaping the recent self-concept of the social sciences. By basing their identity on hermeneutics rather than on the supposed example of the natural 
sciences, the social sciences broke away from the "unity of the sciences" which had been so vehemently defended by the followers of logical positivism. ${ }^{14}$ However, in view of their respective modes of inquiry, I claim this unity can be safely reestablished. In the natural science laboratory, we meet with those features of inquiry which are well known to us from our own social science research operations: (Hermeneutic) understanding is presupposed and interpretation is a constant requirement for establishing, first, what is the case and second, what to do about it. Interaction and communication between scientists (in the field, within an "environment") are a condition as well as an actual characteristic of ongoing research. The laboratory is a "site" in which the local context breeds idiosyncratic interpretations of scientific rules and determines what is done and how the solutions look. Finally, the mechanisms ruling the progress of research are more adequately described as successful "tinkering" rather than as hypothesis testing or cumulative verification. Epistemologically, a constructivist model of the scientific mode of operation suggests itself. In the pages that follow each of these issues is taken up in turn.

\section{The Research Process: Hermeneutic?}

Discussions of "Verstehen" in the cultural sciences usually center around one or more of the following aspects of hermeneutical interpretation:

1) The denial of "brute facts" in hermeneutical processes which holds that data beyond the challenge of rival interpretation are unattainable;

2) The "circularity" of interpretation, which implies an infinite regress such that a given interpretation of any text or event ultimately depends upon yet another set of interpretations;

3) The "language game" aspect of hermeneutics, which conceives of understanding and intirnretation as a condition of the possibility of data in general.

Is there any reason to believe that these aspects are either non-existent, or irrelevant to the conduct of inquiry of the "hard" sciences? Under different names, all components of a hermeneutic procedure as listed above have been demonstrated to affect the very core of the "context of justification"15 in the sciences. The reasons invoked are themselves primarily logical. The question of "brute facts" for instance has long been haunting the philosophy of science as part of a theory of perception and more recently as the thesis of an independent observation language. Theories of perception which start 
from "brute facts" today are almost unanimously rejected, and the thesis of "brute" (theory-free) observation terms has been challenged effectively by the counterexamples compiled by Feyerabend. ${ }^{16}$ As a consequence, new analytic work on the structure of scientific inference accepts the "theoryladenness" of observation, ${ }^{17}$ and general discussion of the issue in philosophy of science increasingly support this position. ${ }^{18}$

More striking, perhaps, is the realization that circularity applies to the context of justification. It has been known for some time that observational statements are not strictly deducible from theoretical hypotheses. ${ }^{19}$ Hence, what is admitted as a fact bearing on a theory can only be established on the basis of certain assumptions. Furthermore, this process is not one of simple bivariate correlation. Operationalization and measurement involve, as another level of interpretation, a series of background theories which themselves need definite justification. ${ }^{20}$ Finally, it has been shown that theories in the natural sciences cannot be required to be fully interpreted, except in relation "to our overall home theory"; our only recourse is to "paraphrase in some antecedent familiar vocabulary." 21 In the end, we are confronted with a situation in which interpretations (facts) can only be explained and justified by reference to other interpretations (on which they partly depend, i.e. the theories) and their relation to the whole (our overall home theory) - an exact definition of a hermeneutical circle. ${ }^{22}$

The third argument cited above ties hermeneutics to the existence of a language game which becomes a condition for the possibility of data. We are reminded of the role played by the cultural grammars we absorb during socialization, and which we routinely presuppose when pursuing our interests. The argument touches on an aspect somewhat different from the question of circularity; particularly, it points to interpretation as something more than a psychological crutch to establish a link between events and experiences. ${ }^{23}$ It is difficult to see how the natural sciences could be denied their share of such presuppositions, expecially after Kuhn coined the notion of paradigm to draw attention to their operation. ${ }^{24}$ Nor will it do to pronounce them irrelevant because of their metaexistence. Language games are not extinct layers of reality; they are constantly acted out and modified in everyday life.

Given the above arguments, is there any evidence from a direct observation of the laboratory which would substantiate the hermeneutical nature of inquiry in the hard sciences? What would we expect this evidence to look like, based on the familiar testimony of hermeneutics in historical inquiry or textual analysis? According to Taylor, the object of hermeneutic inquiry 
presents itself as "confused, incomplete, cloudy, seemingly contradictory in one way or another, unclear." It is "describable in terms of sense and nonsense, coherence and its absence," like the objects of text-exegesis. ${ }^{25}$ In the laboratory, the "texts" are provided by constantly accumulated combinations of measurement traces (graphs, figures, printouts, diagrams, tables, etc.). Objectification through traces in no way eliminates interpretation: such traces must first be recognized; moreover they can be ignored, selected, recombined or simply forgotten in the light of further results or the contingencies of another situation. Consequently, the laboratory buzzes with activity in its attempt "to make sense" and thereby interpret such signs. Needless to say, scientists themselves constantly classify their experience in terms of "what makes sense," and structure their activities in response to questions of how to make sense of their results. Some of this spirit is present in almost any laboratory discussion. For example, ${ }^{26}$

B. is the analytic biochemist in the laboratory. He shows the observer how thin-layer chromatography works: "Of course I cannot know if the stuff is pure just by looking at it .... So I have the spots (B. shows the chromatograph) .... there is a lot of good information in these spots .... You can bend the light like this (turning the chromatograph against the light) ... . There are a lot of tricks ... . But for a lot of reasons which have to do with acceptance and argument, you have to transform the spots into curves." But doing so, B. explains that some information is lost: "When you have your curves, you have a bunch of figures that you have to evaluate, which number is significant and so on ...." Then there is a third step: "Of course I can put the curve on the computer and get the statistical significance. But after that, I have to see if it is interesting." ... "I always have to see by myself if it is interesting."

(sample protocol 1)

"Understanding" is described by Dilthey as an act in which experience and theoretical apprehension are fused. ${ }^{27}$ In contrast, the "explanation" of the natural sciences is thought to "require the application of theoretical propositions to facts that are established independently through systematic observation." 28 If that were indeed the case, why should it be necessary for the scientist described above to employ "tricks," transformations and evaluations to arrive at his "facts"? Why should the "living experience" pay off in scientific research, as it does in translation or ethnography?

In the course of testing the properties of different proteins recovered from unconventional sources, the various proteins were mixed with water and other additives, before undergoing fermentation and heat treatment. In 
each case, the amount of water was fixed to allow for comparisons. While taking some initial measurements of such protein-water mixtures, scientist D. observed, through physical manipulation, that each differed from the other (and from the standard mix) in consistency. Puzzled by this phenomenon, he altered his initial plan and standardized the amount of water used at 500 units, an empirically "established" optimum conventionally employed for the standard mixture. Once his suspicions had been raised, D. began to question the value of the usual method of standardization. Later, he began to vary the amount of water used in the samples prior to fermentation and heat treatment, based on his intuition and the anticipated results. By this method, he hoped to establish the optimum outcome for his tests. When the results failed to match his tentative projections, the process was repeated. Once the optimum amount of water for each protein sample had been determined, he established the alternative units, thus developing a new and significantly different standard for proteins. His questioning of the "standard" method triggered a strong attack against him, since he was disputing a measurement procedure which had been almost universally used for "at least thirty years."

(sample protocol 2)

When questioned by the observer, the scientist said that "certain things can only be realized if you do the experiments yourself." He had done the same kind of experiments six months before with the help of a student, but since he had "never looked at the stuff" in order to check the consistency he "did not get the idea of simply adding more water." Students, as well as laboratory assistants and technicians, not only lacked the experience and the frame of reference, but also the "interest" needed to interpret the signs correctly. The scientist's reference to "interest" points us to the (interest-linked) preconceptions from which interpretation is bound to begin and which are apt to be modified in the process of inquiry. ${ }^{29}$ The notion of interest also refers us to a broader context of relevancies at stake for the agents which cannot be conceived of without making communication and interaction an inherent feature of scientific operations. Communication and interaction are crystallized in two centers of investment: the scientific field and the laboratory site.

\section{The Game against Nature and the Issue of Communication}

In Habermas' discussion of instrumental action, scientific inquiry is characterized by a "restricted language" and "restricted experience." Language is said to be no longer embedded in interaction; similarly, action is held to 
be divorced from communication..$^{30}$ Obviously, this cannot be taken to deny scientists their social being, nor to deny the existence of scientific communities. As had been previously noted by Peirce, the experimenting community of researchers simultaneously corresponds to a semiotic community of interpretation. ${ }^{31}$ If this discourse of scientists cannot be ignored, it can be declared external to "objective science": communication about what one believes and what one wants is accorded the status of a "complementary" metafunction and relegated to the realm of the "conditions of possibility" of research. ${ }^{32}$

Contrary to what one might expect, this picture of scientific inquiry as a monologic game against nature is also sustained in the numerous sociological studies of scientific communities and communication. By assuming that social variables act in addition to or on top of "scientific" (cognitive) variables, independent existence of two kinds of factors is presupposed, even if interaction between them is made the focus of the study. ${ }^{33}$ However, as recently emphasized by Bourdieu ${ }^{34}$ the scientific field is the locus of a competitive struggle for the monopoly of scientific credit - a credit which cannot be partitioned into social and cognitive components nor can it be relegated exclusively to one $o r$ the other realm. The notion of scientific credit as understood here is not to be confused with the "recognition" or "reputation" in studies of scientific communities. "Credit" points toward expected future returns ("promise") rather than to past achievements, it includes the aspect of the credibility of the knowledge claims promoted, and it operates like a commodity of exchange which is constantly re-invested, e.g. converted into money and manpower resources. ${ }^{35}$ Thus credit is linked to the sphere of production rather than to evaluation and control. With respect to the distinction between social and cognitive variables mentioned above, this means that credit must be seen as a symbolic capital acquired through the imposition of technical definitions and legitimate representations of scientific objects, a capital which is at the same time scientific competence and social authority. If scientific controversies within the context of justification are at the same time struggles for social power (i.e. imposing a definition of science is opening up access to resources and positions), how can we eliminate interaction and communication as a constitutive element of the conduct of inquiry? There are numerous examples of scientists who have themselves stressed their vital (or "social") interest as a reason for writing a paper or conducting an experiment ${ }^{36}$; indeed, all major choices seems to be governed by such strategies. ${ }^{37}$

In the course of the protein experiments mentioned above, data on the various chemical and physical properties of the proteins being tested 
had been accumulated. Such analyses are done as a guide to further research which might prove necessary or productive, and because specifications of the respective properties are routinely included in scientific papers. When one of the scientists in charge became interested in a university position with a professor who had established his reputation working on functional properties, the scientist presented his functional property data in a separate publication (not intended before) in order to support his application for the position.

(sample protocol 3)

A scientist once told the observer that he wanted to write a review paper on his current field of research and to offer it to a well-known journal edited near the laboratory. He had heard that this journal was looking for good reviews. Asked why he would want to write such an article, he replied: "Once you've got your name under such a review paper, you have made it as specialist for the area. You will be known as the man for that field. You've made your mark."

(sample protocol 4)

One of the scientists in the group learned from a lecture about a new, very expensive acoustic-electron-microscope the laboratory had acquired. He immediately saw that work with this microscope offered a high (symbolic) profit opportunity, since the microscope was rare and expensive enough to bestow special appeal and attractiveness on any moderately interesting paper including the work with this instrument.

(sample protocol 5)

Not only are decisions regarding a certain line of research, the writing of a specific paper, or the application for a particular position based upon strategies of accumulating symbolic profit, the research itself is executed in a spirit very much in tune with the agonistic ${ }^{38}$ structure underlying the system. This agonistic character is particularly conscious when papers are designed and written so as to avoid or counter anticipated criticism. As might be expected, some types of research are more prone than others to bring this underlying agonism to the surface. Research which is itself critical of "established knowledge," whether by direct attack or an indirect discounting of previous procedures, will meet with a more contentious response than will research which remains in accord with the ruling opinions.

In a discussion between the head of a laboratory and a co-worker, it was agreed that different results recently obtained would be published in two separate papers because of their respective "importance." One set of results seemed to refute the widely accepted "dilution theory" which 
attributes the behavior of certain proteins in a protein mixture to a dilution effect which has consequences for the functionality of the blend. The second set of results (mentioned above) involved a questioning of measurements in regard to protein-water mixtures. The head of the laboratory commented that both papers would get everyone involved "into trouble." In regard to the attack on dilution theory, the co-worker who established the results said that "they will tear us to pieces" because the life of a "fully accepted theory" was at stake. In the second case, he said that "everybody will be furious because they didn't think of it themselves . . . It's too simple." One of the most frequently encountered objections (and one expected in the above two cases) is that the results "only hold under special conditions" and are limited to the specific types of material used in the experiment.

One of the scientists commented on the situation in the following way: "If you are in accordance with a theory, you have only to make one repetition and to study one product .... and everything is fine .... If you are not, you had better take great care with what you do, and how you do it."

(sample protocol 6)

The discourse of scientists, whether contentious or innocuous, is always anticipated and built into the procedure of research. If results are judged to be non-controversial, the standards are set at a low level, as implied by the remark in the above example. In the case of impending criticism, a special presentation of the results might be arranged for an internal audience, or "severe critics" found for an internal review of the paper, in order to better identify the expectable counterarguments. In the above example, the research was extended to include tests conducted under more complex conditions, in order to head off the anticipated "non-generalizable" argument. However, such activities are often exclusively oriented towards legitimation. The researcher moves cautiously in order not to endanger the original "good" results: the conditions chosen to meet the "more complex" requirement were such as to clearly increase the chances of an outcome compatible with what had been found in the more simple case.

\section{Bringing Space and Time Back in: The Laboratory Site}

The scientific field invoked in the above paragraph sets the scene for the moves which scientists make. Being in a sense the aggregation of these moves, the field has a constantly changing shape and fuzzy borders. ${ }^{39}$ In general, the 
field also has an aura of being nonlocal and international. Considering the linguistic, paradigmatic, publication related and other barriers to internationality, this image is unwarranted. Always ahead in their strategies of the sociologists who investigate them, scientists play on these very limitations of the field in order to improve their originality.

During a discussion on further projects and plans, one scientist told the observer about a Russian paper "that hopefully nobody knows here" which suggested that the results of tests the scientist was currently involved with might be significantly improved by using a particular plant juice. The idea seemed sufficiently profitable (which it would not have been if the use of the juice were an established or well-known device) to give it a try, even if only a "rough and dirty" one.

Questioned by the observer, the scientist said that he would cite the paper in a future publication. Thus, no violation of scientific "ethics" is involved; ideas need not be stolen in a universe where there is hardly any repetitive or replicative research. Although this cannot be substantiated here (see also below, footnote 47) it is held that analogical reasoning and analogical transference of "ideas" or solutions from one research context to another play a key role in successful research practice. In the above case, the use of the plant juice was transfered from a context distinctive in most respects, but at the same time sufficiently similar to make the use of the juice appear as relevant, "workable" and as a "solution".

(sample protocol 7)

Local contingencies are much more obvious if we consider the actual site of the research, the institution and the laboratory. To establish the transition from the field to the laboratory, it is tempting to invoke an ordered relationship: the laboratory site can be seen as providing the means through which scientists pursue the interests at stake on the level of the field. However, it is obvious that those interests are also shaped, articulated and initiated by the opportunities and possibilities provided by the institution. Fields are changed in order to better cope with the contingencies of an institution, and institutions are changed in order to better pursue one's investments in a field. Any neat separation of the two from the point of view of scientific action seems fruitless and artificial. Can we say that field and laboratory-site together determine scientific operations? It would seem more likely that research products derive their existence from the possibilities and opportunities, the ambiguity and overall slack within the system in which they originate. This slack creates a contingency-space from which alternative scientific developments constantly emerge and decay. Research products bear the mark of this 
disorder. They are 1) multifaceted hybrids generated from 2) what was locally available and from 3 ) what assumed significance under a given constellation of the field and the immediate environment.

In the laboratory, this slack manifests itself in the constant negotiations and manipulations of resources and interests, or in mobilization and subversion strategies:

The research institution observed maintained several large-scale laboratories especially equipped a) for the production of low-yield substances whose properties would rule out normal laboratory operations and b) to partially simulate the conditions which exist in industrial practice. One of those laboratories was headed by scientist $\mathrm{K}$. who routinely used it for protein recovery tests during part of the year. This scientist made it extremely difficult for anyone else to use the laboratory (even during the so-called "dead season") despite the official rule that laboratories and equipment in the hands of any specific scientist had to be made available to everyone else. Thus, $\mathrm{K}$. (whose reputation was international) had subverted the official policy and thereby created a state of disorder in which anything was possible, depending upon individual negotiations and manipulations.

For scientist D. (who had only arrived at the institute a few months earlier), the existence of K.'s laboratory represented a tremendous opportunity, since such resources were quite scarce. D. had no trouble using the laboratory the first time, since $\mathrm{K}$. was interested in observing his procedure (also directed toward protein recovery) and acquainting his staff with it. On the second occasion, D. tried to gain access to K.'s laboratory without K.'s knowledge, since it was well-known that $\mathrm{K}$. insisted he be a co-author of all papers based on research done in his facilities. D.'s "excuse" was that he had run out of protein; his actual intent was to add a very important step to the procedure which would alter the color and biological value of the recovered protein. When $\mathrm{K}$. was officially asked for "his" laboratory, he threw up the expected roadblocks, finally agreeing to a "lab" date which left D. too little time for preparation. With the aid of co-workers, $\mathrm{K}$. made sure that $\mathrm{D}$. adhered to the exact procedure he had used initially. D. tried to either smuggle his step into the procedure or negotiate with the laboratory staff for its inclusion, but failed. As a result, he had to abandon his original plans.

Some months later, K. read D.'s published results from the initial trial (K., of course, was a co-author, since his lab had been used). Afterwards, 
K. urged D. to repeat his tests, which D. saw as an attempt to make sure that the procedure worked and that his own staff was thoroughly familiar with it. D. agreed to this after deciding to include the additional step once again in a revised version which he thought would go unnoticed. This effort met with success.

(sample protocol 8)

For the present purpose, this example shows how slack in the rules, resources and power constellations of an institution could be exploited both by $K$. and by $D$. with mixed results in terms of their own interests, leading to research outcomes that were defined by what could be done and how it could be done. Despite his power, K. could not simply replace one rule with another more to his liking. His decision (also subject to slack) to deny laboratory access to all external interests allowed for outcomes which could work against him, as happened when D. subverted K.'s interests in his own favor and again when $K$. failed to see that D.'s results were relevant to his own research.

\section{Local Idiosyncracies}

There are many other examples in which spatial-temporal contingencies bear on how the research results are created. Some are so routinized as to be hardly noticeable, as when local employment regulations prohibit testing after $4: 30 \mathrm{pm}$ or on weekends, so that freezing and storing procedures not specifically mentioned in the resulting papers must be used to compensate for these unmethodical interruptions. Others refer to the larger context, as when a filtration technique is preferred over centrifuging because it saves energy, or when for similar reasons, a chemical method working at room temperature is extensively tested with the hope of replacing a heat coagulation method. ${ }^{40}$ Perhaps more interesting for the sociologist or historian who expects to find such "external" influences are the local idiosyncracies which develop - a phenomenon almost completely ignored in the literature on science. Like any other organization, research sites develop local interpretations of methodical rules, a know how referring to what is meant and how to best make things work in the face of a codified literature. ${ }^{41}$

The research institution under observation included several "service" laboratories whose main function was to perform routine analyses of chemical composition required in many research efforts. Coming from another environment, Scientist D. was surprised to find that these tests were performed without replication, apparently under the assumption that such measurements were standardized routines without risks or uncertainties. 
D. brought with him a contrary interpretation: measurements become routine precisely because they are important, which means that precision is their foremost requirement. He illustrated his point by citing the fact that single ingredients in a product are reported as percentages of the dry substance of that product, which means that the "routine" measurements of the dry substance need to be very precise and reliable. Based on this, D. said: "When I read one figure in the literature, I would automatically assume that I have been confronted with a mean value."

(sample protocol 9)

In this case, each side stuck to its interpretation. The scientist repeatedly asked the analytical laboratory for the same analysis twice, using different codings for the sample so as not to raise their suspicions. The clash of two locally developed systems of interpretation only became apparent when the expectations of a scientist transferred from one system to the other were constantly violated.

Local idiosyncracies also bear upon questions of composition and quantification, e.g. questions concerning how much and what kind of ingredients are used in a test. Standard formulations of what and how much to use exist for certain areas, but are usually rejected by the scientists themselves because they lag too far behind current knowledge: it takes too much time for a method to become an officially acknowledged standard procedure. The material used in experimentation provides an additional source of local variation, since it will often be locally grown (plant material, organisms, etc.) or produced (chemical substances, etc.):

The protein mentioned earlier had been recovered from a local plant variety. When exposed to various treatments, differently processed versions of the protein were mixed with several other ingredients. Their number and quantity reflected the respective scientists' attempt to achieve maximum control, their knowledge of what quantities had been used with what outcomes in previous research, and their bets on what might be successful. For the reason mentioned above, the existing standard formulations were rejected.

If the formulation of the samples in this case indicates the guesses and concerns of the two scientists involved, the procedure used was largely influenced by routinized local interpretations. As an example, the time needed to manipulate the mixture before it was put into a fermentation cabinet was counted as belonging to the "fermentation time," while in other contexts it figures separately. In the same test-series the volume and 
weight of the mixtures were measured immediately after they had been submitted to heat treatment. According to the scientist who came from another context, this was "problematic," since the volume changes during the cooling period. Thus, the results depend upon when the measurement is taken. In general, the time during which the test material was subjected to a procedure was based on local knowledge of what works best, a phenomenon which accounts for the wide variations of results in the literature. The treatment of ingredients before experimental use also illustrates local differences. In the above laboratory, the microorganisms used for fermentation were used for several weeks, while at other locations they are exchanged after one week.

(sample protocol 10)

The above argument can be extended to include measurement devices and instrumentation as further sources of potentially local variation. Obviously, at least part of this information is routinely provided in papers by indicating brand names, identifying firms, or describing the procedure. The argument here is not that science is private or that scientific results cannot be replicated, but rather than the information obtained is idiosyncratic, reflecting choices and interpretations that are crystallizations of order in a local contingency space. Contrary to what we might think, criteria of "what matters" and "what does not matter" are neither fully defined nor standardized throughout the scientific community; nor are the rules of official science exempted from local interpretation. In general, these interpretations refer to at least three areas of decision:

1. Composition, i.e. questions relating to the selection of specific ingredients and instrumentation;

2. Quantification, i.e. the question of how much of a substance is to be used in a test, how long a process should be maintained, when a measurement or a sample ought to be taken during an on-going experiment, etc.; and

3. control, i.e. such methodological options as simplicity of composition vs. complexity as an approximation of practice, or strict vs. indirect comparability in the case of potential interaction between the instrumentation and the experimental material.

With these choices in view, research cannot be partitioned (as Weber tried to do) between an externally influenced selection of the research topic and its internal, objective (standardized) execution. The choices exist throughout the process of experimentation: there is no core of information which could, 
in principle, be left unaffected. Scientific "facts" are the hybrids constructed by means of those choices in which the composing rationalities and contingencies can no longer be differentiated. ${ }^{42}$ Their originality and their distinctive value (in the information theory sense of low expectancy) derive from the idiosyncracies which mark their production. ${ }^{43}$ If there is nothing actually or "essentially" 44 monologic about scientific action, there is also nothing actually or essentially repetitive. And why should there be? Scientists do not strive for repetition, they aim for distinctiveness. ${ }^{45}$

\section{The Alternative Model: Successful Tinkering and the Dynamics of Research}

I have described the scientific fact as an idiosyncratic hybrid and argued for the hermeneutical and agonistic (not dialogic) character of the process of inquiry which produces this fact in the slack of a historical contingency space. Granting interaction, interpretation and idiosyncracy, is there anything which precludes us from applying the vocabulary of verification, hypothesistesting and truth to this process? So far I have not directly addressed the underlying logic of inquiry, or the guiding principles of the research process. As might be expected, the experience of the laboratory proves that the model of hypothesis-testing spread by methodology textbooks and theoretics of the social sciences is inadequate; the scientific agents must be returned to the picture, and the dynamics of the process brought back into focus. In the following pages, some of the most apparent features of this process as experienced in the laboratory will be summarized.

\section{The Start - Solution or Hypothesis?}

In successful tinkering as a mode of operation, the scientist begins with what might be called an asset: i.e. a perceived solution which raises the question around which the paper will later be organized, an advantage he secures on the level of instrumentation or interpretation, or an opportunity for success from which he moves backward in order to actually "make the stuff work." Such assets include what catches one's eye as a "striking new idea" when read in a paper, or the promise of a successful criticism. In the following example, a metaphor established such a promise together with the purpose it would supposedly serve:

In the context of a discussion between two colleagues as to the whereabouts of a particle-surface measurement devise, the question arose as to how one might explain the differing properties obtained for proteins 
which had been subjected to different drying methods (i.e. varying degrees of exposure to high temperature). One of the scientists cited the denaturation of the protein brought about by exposure to high temperatures. A second scientist confirmed this by stating that protein subjected to the most extreme heat treatments produced results very much like those obtained from a highly inert (denatured) non-protein standard product. The hardness of the respective particles was then introduced into the discussion, whereupon the scientist most involved with the protein tests noted that the extreme heat-treated protein "looks just like sand." Struck by this simile, the scientist immediately changed his plans and began a series of experiments to compare the results of different treatments in reference to sand-diluted and protein-diluted mixtures. The procedure had struck him as a possible "solution" to a problem raised by the simile itself, i.e. the questioning of the prevailing "dilution theory" which was made a research topic in its own right. If there were no differences between the sand-diluted and protein-diluted mixtures, then the dilution theory would be confirmed. As we know from a previous example, the theory was not confirmed. (The paper disproving the theory is currently in press). Experiments designed to establish an alternative theory are currently underway.

(sample protocol 11)

The following example provides a variation on the theme; in this case, the problem existed beforehand, but became a research focus only when a "solution" was hit upon:

The scientist mentioned in the above example was occasionally plagued by an expectably high level of a toxic compound in his protein samples. He made several attempts at having the existing sẹrvice laboratory determine its content and search the literature for some method of handling the problem. All efforts were unsuccessful. The problem was eventually put off and intentionally ignored, as it had no bearing on the research already underway nor on projected publications. Later, the scientist decided to make the elimination of the toxic compound (which at that point was still undetermined) a byproduct of more pressing research on the elimination of an additive used during protein coagulation. Since this would require a slightly elevated $\mathrm{pH}$ value, he discussed his idea with scientist $\mathrm{H}_{\text {., }}$ who had worked with the reported compound for years. H. felt that the method showed no promise of success, but suggested that an enzymatic procedure had worked in respect to a different plant. $\mathrm{K}$. immediately picked up the idea, later telling the observer that "I think I have the advantage of being the only one who got the message from $\mathrm{H}$., and the only one to understand its implications (i.e. H.'s method had 
worked with another plant and another toxin which was analogous with but not identical to the above mentioned) . . . In principle, $\mathrm{H}$. would be willing to work with me if there is time." $K$. could not perform the necessary experiments on his own since he needed the know-how belonging to the other laboratory. Consequently, the chances of H.'s suggestion becoming a solution for K. depended on H.'s willingness to cooperate.

(sample protocol 12)

As both examples suggest, the operation of opportunities for success in no way eliminates search processes, long periods of experimentation or the pursuit down blind alleys from the research process. After all, the "solutions" hit upon have not yet been worked out; in the process of making them work, new problems constantly arise and investments once made on the basis of a perceived solution tend to stabilize the effort around the "promise" even in the face of recalcitrant experience. The role of "solutions" and opportunities for success lies more with their driving and orienting function than with anything else. As a driving force, they push the research process forward, lending it a projective orientation. As an orienting force, they determine the direction of the process. The difference between a hypothesis and a "solution" or promise of success consists mainly in the practical, almost material character of the latter, i.e.:

1) it is highly probable that the "solution" will work or can be made to work technically and organizationally; and

2) there is a good chance to reap symbolic profit (e.g. through publication) based upon the distinguishing features of the results (both in terms of their quality and their difference).

Opportunities for success do not refer us to the imaginary world of ideas and theoretical interpretation which we commonly associate with hypotheses; the standard against which they are measured is not explanatory value. Rather, what is at stake in opportunities for success are questions of resources and instrumentation, timing of publication and expectations of agonistic response. The notion of hypothesis-testing fails to convey any of the connotations which prove productive in conceiving of the research process. Does this mean that "truth" itself becomes irrelevant?

\section{The Goal: Truth or Success?}

Indeed, the notion of success so often invoked in the last paragraph does not seem to have much in common with the prevailing definitions of "truth." 
In the language of hypothesis-testing, "truth" (in its correspondence-theory version) will assume the role of a goal value and lead us to the concepts of description and empirical confirmation. In contrast to "truth," the notion of success is tailored to an actual mode of production. Specifically, (1) success is for and by an agent - it is tied to an interest structure. Furthermore, (2) success is carried by instrumentation and organizational objectivation - the process is material. Consequently, (3) theories are subordinated under more general and different strategies - the policy aspect of success. In addition, (4) success is heavily dependent on what is available in an environment, thus it is opportunistic. (5) Success points into the future - the process is generative rather than feedback-oriented. Finally, (6) success is actually cashed out - its conditions are satisfied in actual research. Most of these aspects have been partly exemplified in previous quotes and paragraphs to which I will refer. In addition, they sketch insights gained in long term laboratory observation, to be expounded in more detail in the future.

1. As illustrated by the process of negotiation between $\mathrm{K}$. and D. in sample protocol 8 and more generally by most examples cited in the beginning (e.g. 3-7), "success" must be seen as inherently tied to an interest structure: it simultaneously refers to the struggle of scientists for symbolic capital and to the production of scientific results. The latter are perceived in terms of their "cash value" transferred by publication or other means. ${ }^{46}$ In contrast to success, truth has as its main referent the system of ideas and the structure of reality reflected in those ideas. What counts as true, one will readily admit, depends on the state of this system of ideas (the accumulated knowledge). But what counts as a success or the opportunity for a success also depends on the structure of the scientific field and the position and symbolic resources of the scientist within that structure. In the example based on elimination of a toxic compound, $\mathrm{K}$. saw an opportunity for success in what was of no interest to $\mathrm{H}$. Despite the fact that each addressed the same problem area (of the compound-elimination), the different relevancy structures of their respective specialities and their dissimilar career positions $(\mathrm{H}$. was approaching the end of his career, $\mathrm{K}$. was just beginning his own) engendered variant definitions of success. Unlike "truth," "success" is never absolute or general; it is always for a particular agent at a particular time and place (where time and place includes more than the current state of knowledge).

2. The "materialism" of a process oriented toward success rather than truth points to two dimensions: that of practice and that of objectification. As argued previously, success is inherently linked to making things work in practice, i.e. instrumentally and organizationally. Indeed, the process 
often starts from a purely instrumental or organizational advantage, as when the existence of an acoustic-electron-microscope gave rise to a research topic which would allow the scientist to use it (sample protocol 5), or when a variety of tests routinely offered by service laboratories are exploited and skillfully assembled into a special publication (protocol 3). "Pure" assets of information are equally material: a clue from the liter. ature as in the case of the "Russian" paper (protocol 7) or an unspoken conclusion drawn from a discussion with colleagues as in the case of the protein-sand comparisons (protocol 11), an earlier side result of a measurement or an interpretation indexed by the outcome of a test (protocol 2) - all can be perceived as opportunities for success precisely because they "worked" in another case from which they are inferred through analog reasoning, 47 or because they are felt to be "workable" given available knowledge and instrumentation. There is a second dimension of practice: assets of information will be stored and potentially "forgotten about" if they cannot be translated into research results in a satisfactory way under the given circumstances. ${ }^{48}$

Objectification describes this same materialistic phenomenon in terms of the constant production of new scientific reality. In the laboratory, there is an ongoing transformation of "ideas" (in the sense of interpretations) into measurement traces and new scientific objects, which are in themselves the signs which index further transfiguration. In the process, ideas are not only transformed through instrumentation, but also take on "value" by being objectified. The objects are made comparable by being materially reduced to a common denominator (the language of measurement). ${ }^{49}$ Through their newly acquired reality, they can be stored and exchanged. Moreover, they are invested with the "faith" we have in the objectivity of objects.

3. If the process of research was called "material," theories must be considered "atheoretical" in inquiry: they do not enter into the research scene in any of their more traditionally solemn guises. The laboratory versions of theories are the partial interpretations which abductively (Peirce) furnish "what is the case" classifications as discussed in the paragraph on the hermeneutical character of research (see also sample protocols 1 and 2). Interpretations are routine responses to experimentation and are kept alive only through successful objectification in subsequent measurement. To call theory "atheoretical" in scientific operation means that it is not divorced from its practice; it expresses crystallized (experimental or mathematical) activities, and is in turn woven into the process of performing these activities. The alienation between theory 
and practice which figures so prominently in the social sciences is suspended in the "hard" sciences in favor of an action-cognition mesh to which the term theory can no longer be adequately applied. Guiding devices ${ }^{50}$ in the research process take on the character of policies rather than creeds. $^{51}$ These policies mesh interpretation with strategical and tactical calculations, and they are carried out by methodological how-todo-it projections. Like success, policies have to be tied to an interest structure. Pure theory, one could say, is an illusion which the sciences have retained from philosophy. ${ }^{52}$

4. The opportunism of a process guided by success rather than truth as illustrated in sample protocols 5 or 8 , but also 9 and 10, derives from the fact that success depends heavily on the opportunities offered at the research site and its environment. It is important to see that the goals realized in research are not the pre-given ends which science transforms technologically. ${ }^{53}$ The instrumentality of scientific action does not consist in scientists supplying the instruments for independent objectives and utility functions. ${ }^{54}$ As argued, the products of science are the successful "happenings" in a historical contingency space mapped out by the relevancy structure of the field, the (instrumental and informational) "holdings" of the laboratory site (itself dependent on an environment), and the scientist's position within this structure. Consequently, this opportunism is less that of the scientists than of science itself; it refers to a mechanism dictated by the dominating struggle for scientific credit, and to local variability with respect to what is ready-to-hand and what counts as an advantage.

5. In a process carried on by historical opportunities at a local site and driven by solutions rather than hypotheses as we have argued, the rhythm is generative. Generativity as understood here does not preclude publication in terms of the refutation of a certain theory or procedure as intended in the example of water standardization (protocol 2) or in the case of the protein-sand comparisons (protocol 11) - including the agonistic aspects of such undertakings as presented in sample protocol 6 . The dynamics of the research process requires that the laboratory be seen primarily as a device for generating new scientifc objects (some of which will eliminate previous ones), and not primarily as a retrospective testing device for past knowledge claims whose origin is relegated to the context of discovery and thought to be unexplainable. ${ }^{55}$ The role of recalcitrant experimental outcomes or side results such as described in protocol 2 consists primarily in indexing future alternative procedures or particular search processes, whose results are often immediately translated into new 
experimentation (see also protocol 11 above). Generativity also refers to the overall openness of the mode of operation. Solutions are constantly modified, and generated in the very process of making them come true. The picture presented by the sum of measurement traces undergoes continuous change in its form and structure. While loose projections lend coherence to this structure, what will make up a separate publication falls into place only after the fact.

6. Finally, success has none of the "absolute" quality attributed to the notion of truth. In contrast to truth as a goal never quite achieved, success is constantly cashed out (e.g. through publications accepted) and accordingly reinforced as a selection principle. ${ }^{56}$ Indeed, the system can be said to be overdetermined; the conditions of success are satisfied by more than one combination of variables under almost any set of circumstances. Furthermore, it can be plausibly argued that human agents, in science as elsewhere, tend to "satisfice" rather than maximize. ${ }^{57}$ Whether dealing with career considerations or technical operations, they will make do with the "first best" solution. Clearly, this would make success an even more stable feature of scientific everyday life. But what are the conditions of success which can be so easily met when truth is called upon as a frame of reference? Operationally, successes are the recognized assets in the profile or scientist's symbolic credit. Partially objectified through curricula and lists of publications, these assets may be the focus of theories of scientific agents like the one outlined by Bourdieu. ${ }^{58}$ In the research process, however, success leads a peculiarly phantasmagoric existence. Always projected or retrospectively interpreted (cash-outs are the breaks between projection and reinterpretation), success can never be fully tracked down and given permanent identity.

\section{The Prospect: Tinkering and Constructivism}

A satisficing mode of operation in which successes are achieved routinely through experimenting with locally existing opportunities invokes the image of tinkering. ${ }^{59}$ Projective openness and the material character of operation and outcome add to the picture. In the process of coping with adversary situations, scientists divert tools away from their original function, as when a pressure meter is used to determine gas absorption capacity, or when the lack of a density measurement device is overcome through centrifugation combined with volume measurements. What is ultimately produced in tinkering relates to clearly defined project-tasks mainly through the staged presentation of the published paper. As a result it makes no sense to conceive 
of those productions as "optimal" in the generally accepted sense of the word.

By invoking the image of tinkering, I do not mean to impute to scientists anything like poor habits of thought or procedure. As already stated in the case of opportunism, the features and mechanisms alluded to describe a process (research) rather than individuals and their attitudes or operations. Nor should tinkering be seen as the result of the particular kind of research problems dealt with which in the present case were biochemical and technological. Rather, the point is that the process of research in its dependency on local opportunities includes all the characteristics of a practice found elsewhere in human activities; in particular, the "rationality" which we might want to attribute to those activities presents itself as tinkering, when seen as embedded in this practice. On a global level, the practice of scientists contructively generates a new reality, that of research findings and their material correlates. This reality is not built from scratch: sophisticated measurement devices, chemical reagents and ingredients, specifically bred test-animals and plants, symbolic and mathematical procedures - all constitute a highly constructed and multiplely selected reality resulting from previous scientific activities.

The constructed character of scientific reality suggests an interpretation of knowledge which directly relates to the question of scientific realism. ${ }^{60}$ Empirical observation and experimentation can be seen as means for confronting our hypotheses with the reality of what is and thereby advance us toward a progessively better understanding of nature. However, scientific activities can also be seen as a progessive selection of what works by using what has worked in the past and what is likely to work under the present, idiosyncratic circumstances. Scientists make the world in which science is verified, and they make it by material, technological transformations of reality. ${ }^{61}$ The constructions obtained do not result from necessity: the same problems tackled in a tinkering process are likely to lead to outcomes which differ according to the idiosyncracies of their production.

A constructivist interpretation of knowledge is not to be confused with an idealist ontology: I do not maintain that reality is produced (constructed) in the sense that its appearance has no independent existence. Rather, this approach claims that once we see scientific products as selectively carved out, transformed and constructed from whatever is, we will also see that there cannot be any warrant in the claim that we have somehow captured (subject to progressive improvement) what is. The question, so puzzling to the sceptic, of why our interest-geared instrumental conceptions of nature should some- 
how match its inherent structure is misconceived. Scientific reality is multiplely constructed in virtue of its matching the structures imposed by scientists. In the picture which emerges "interest," "success" and a constructive rather than descriptive methodology are key-dimensions which characterize the research process as a practice. Theories are the cocoons left behind when practice is abstracted from the conduct of inquiry; since this practice includes the discourse of specialty fields, not even a paper reality can be accorded to them.

\section{NOTES}

1. But also in the "Cunning of Reason" associated with history by Stephen Toulmin, Human Understanding, Volume 1 (Oxford, 1972), or in the quasi-automatic of cross-control mechanisms, an idea taken from Polanyi and recently emphasized by Pierre Bourdieu, "The Specificity of the Scientific Field and the Social Conditions of the Progress of Reason," Information sur les sciences sociales 14 (1975), pp. 19-47.

2. The challenges were of a logical and empirical kind: as early as 1906, Duhem questioned the distinction between a theoretical and an observational language, which later figured prominently in the criticism of logical positivism. See Mary Hesse, "The Structure of Scientific Inference (Berkeley, 1974), p. 2. The historical examples of Feyerabend and Kuhn might serve as paradigmatic cases for the second type of challenge. See Paul K. Feyerabend, Against Method (London, 1975), and Thomas Kuhn, The Structure of Scientific Revolutions (Chicago, 1962).

3. See for instance David Bloor, Knowledge and Social Imagery (London, 1976); Pierre Bourdieu, op. cit., pp. 20 ff; Harry Collins, "The Seven Sexes: A Study in the Sociology of a Phenomenon or the Replication of Experiments in Physics," Sociology 9 (1975), pp. 205-224; Paul Feyerabend, op. cit., particularly chs. 1-5 Karin D. Knorr, Hermann Strasser and Hans Georg Zilian, eds., Determinants and Controls of Scientific Development (Dordrecht, Holland, 1975), Introduction to part II; Roger Krohn, "Scientific Ideology and Scientific Process: The Natural History of a Conceptual Shift," in Sociology of the Sciences, Volume 1 (Dordrecht, Holland, 1977); Bruno Latour and Stephen Woolgar, Science in the Making (Beverly Hills, 1978), Everitt Mendelsohn, "The Social Construction of Scientific Knowledge," in Sociology of the Sciences, Volume 1 (Dordrecht, Holland 1977); Ian I. Mitroff, The Subjective Side of Science (Amsterdam, 1974); Nico Stehr, "Zur Soziologie der Wissenschaftssoziologie," Kölner Zeitschrift für Soziologie und Sozialpsychologie, Sonderheft Wissenschaftssoziologie 18 (1975), pp. 9-18; Peter Weingart, "Wissenschaftlicher Wandel als Institutionalisierungsstrategie," in Peter Weingart, ed., Wissenschaftssoziologie 2, Determinanten wissenschaftlicher Entwicklung (Frankfurt, 1974).

4. A good overview of critical rationalism and some of its counterarguments is: Imre Lakatos and Alan Musgrave, eds., Criticism and the Growth of Knowledge (Cambridge, England, 1970). The structuralist conception is represented by Michel Foucault, for example in his The Order of Things (New York, 1970), or in his The Archeology of Knowledge (New York, 1972). For Bourdieu see op. cit., and the underlying more general theory in: Pierre Bourdieu, "La production de la croyance: contribution a une economie des biens symboliques," Actes de la recherche 13 (1977), pp. 3-43. The most pronounced evolutionist is: Stephen Toulmin, Human 
Understanding, Volume 1 (Oxford, 1972). The sceptical position is represented most consistently in the writings of Paul K. Feyerabend, op. cit., or "Explanation, Reduction, and Empiricism," in Herbert Feigl and Grover Maxwell, eds., Scientific Explanation, Space and Time, Minnesota Studies in the Philosophy of Science, Volume III (Minneapolis, 1962), pp. 28-97.

5. The institution is located in Berkeley, California. According to its official directory, it employs more than 300 scientists (along with an additional technical and service staff) working on basic and applied problems in chemical, physical, microbiological, toxicological, technological and economic research. Most of the scientists hold degrees in biochemistry and in one of the above areas. The observations focussed on work involved with plant proteins, an area which turned out to include a variety of questions and disciplinary approaches (such as generation and recovery, purification, structure, texture, biological value, and additives). Reports, comments and citations have been taken from my notes, and their accuracy has been verified by the scientists involved. Each example given is by way of illustration, standing for many others of its kind. Although the name of the institution and scientists cannot be given for reasons of confidentiality, it should be mentioned that the institution holds excellent equipment and is demonstrably successful with respect to the number and quality of publications and patents. For instance, the scientist most actively involved and responsible for the protein experiments mentioned, during the year of observation produced 9 new publications, 4 of them were review articles, 5 of them included original research results published in the most relevant journals in the area. The supervising group leaders often have an outstanding reputation throughout the field on an international level.

6. The notion of labor, although not commonly used in English translations of Habermas, would be more appropriate here, since it directly refers to the "productive Eros" (Baudrillard) of Marxist theory in which labor is "an ontological concept of human existence as such" - see Herbert Marcuse, "On the Concept of Labor," Telos 16 (1973), pp. $11 \mathrm{ff}$. Habermas attempts to overcome this limitation in Marxism by additively annexing symbolic interaction to labor (instrumental action).

7. Jürgen Habermas, Knowledge and Human Interests (Boston, 1971), pp. 189 ff.

8. The distinctive feature of hermeneutic interpretation is often described as a circular part-whole relation: The interpretation of partial expressions depends on those of others, and ultimately on the whole, while the reading of the whole can only be established by interpretations of partial expressions. See for example, Charles Taylor, "Hermeneutics and Politics", in Paul Connerton, ed., Critical Sociology (New York, 1976), p. 156.

9. Habermas, op. cit., p. 176.

10. Peirce uses the example of the predicate "hardness" in the case of diamond, which is entirely constituted by the fact of another stone being rubbed against it. The hardness of the diamond is independent of the rubbing, yet the attribution of the predicate "hardness" is only meaningful with regard to possible instrumentation. See Charles S. Peirce, Collected Papers, Volume 5 (Cambridge, Mass., 1931-35), p. 457.

11. Martin Heidegger, Being and Time (New York, 1962).

12. The hammer serves as an example: it is one of the "ready-to-hand" objects of everyday life which is perceived in terms of its function; in science, however, the hammer is dissolved into properties of wood, metal or plastics, into chemical structures and physical laws.

13. Clearly, scientific predicates only make sense within the referential totality of scientific knowledge and instrumentation, which is in itself embedded in our home-language and in the structure of industrial society.

14. The discussion on the methodological self-conception of the social sciences is 
exemplified in books like: Paul Filmer, Michael Philipson, David Silverman and David Walsh, New Directions in Sociological Theory (London, 1972); Anthony Giddens, Positivism and Sociology (London, 1974); Paul Connerton ed., Critical Sociology (New York, 1976). Ethnomethodology, symbolic interactionism, teflexive sociology, cognitive anthropology, ethnoscience, or the pragmatic direction of recent linguistics provide examples for such a hermeneutic self-conception.

15. The distinction between the context of discovery and the context of justification is of little use when looking at actual research (see below). The context of justification is emphasized here in order to avoid the argument that the hermeneutical character of natural science research is discredited by granting its validity "only" for the context of discovery.

16. See Paul K. Feyerabend, "Explanation, Reduction and Empiricism," op. cit., and Against Method, op. cit.

17. See for example Mary Hesse, op. cit., particularly the Introduction.

18. Arguments for and against theory-ladenness of observation as well as discussions of other contentious issues in recent philosophy of science are published and summerized in: Frederik Suppe, ed., The Structure of Scientific Theories (Urbana, Ill., 1974).

19. Hence the discussion on the nature of the "rules of correspondence" which were supposed to establish the link. See Ernest Nagel, The Structure of Science: Problems in the Logic of Scientific Explanation (New York, 1961).

20. See Willard v.O.Quine, Ontological Relativity and Other Essays (New York, 1969), pp. $69 \mathrm{ff}$., and Imre Lakatos, "Falsification and the Methodology of Scientific Research Programs," in Imre Lakatos and Alan Musgrave, eds., Criticism and the Growth of Knowledge (Cambridge, England, 1970), p. 99.

21. Quine, op. cit., pp. $48 \mathrm{ff}$. In practice, we end the regress of background languages "by acquiescing in our mother tongue and taking its words at face value" - see Quine, op. cit., p. 49. In this earlier work, Quine had already proven that no single theoretical statement can ever be refuted by an empirical counterevidence. See for example Willard v.O.Quine, Word and Object (Cambridge, Mass., 1960).

22. See for example Charles Taylor, op. cit., p. 164.

23. In this light, Abel's famous attempt (1953) to eliminate hermeneutics from the context of justification in the natural sciences by relegating it to the "prescientific" art of discovering hypotheses misses at least part of the point. See Theodore Abel, "The Operation Called 'Verstehen'," in Herbert Feigl and May Brodbeck, eds., Readings in the Phiolosphy of Science (New York, 1953), pp. 677-688, and Karl Otto Apel, "Scientistik, Hermeneutik, Ideologiekritik," in Jürgen Habermas, ed., Hermeneutik and Ideologiekritik (Frankfurt, 1971), p. 21.

24. See Kuhn, op. cit., pp. $10 \mathrm{ff}$. In recent discussions of the methodological status of the social sciences, there is a tendency to stress the hermeneutical nature of their object domain, for example throughout the discussion presented in Filmer et al., op. cit. However, Dilthey raised the objection that different regions of fact do not "exist"; rather, they are constituted. Hence, a circumscription of the object domain does not suffice for a logically cogent delimination of the two groups of sciences. See Habermas, op. cit., p. 141.

25. Taylor, op. cit., pp. $153 \mathrm{ff}$.

26. This example was kindly provided by Bruno Latour to document the identical character of the relevant results which emerged from his observation-study done at a major research institution in San Diego, California and from my own research. Latour's data support the thesis of the hermeneutical character of natural science research, and in general all major points made in the present paper (written communication). For a presentation of his study, see Latour and Woolgar, op. cit.

27. Wilhelm Dilthey, Gesammelte Schriften, Band 5 (Goettingen, 1913-67), p. 143.

28. Habermas, op. cit., p. 144. 
29. According to Gadamer, historical and existential involvement is a condition of the possibility and validity of hermeneutic understanding. As a model Gadamer proposes the "applicative" understanding of the judge: the binding character of tradition is not dissolved, but mediated with the present, and interpretation is oriented toward application in a practical situation. See Hans Georg Gadamer, Wahrheit und Methode (Tübingen, 1965). The model of the judge has been challenged as a fruitful metaphor in the case of the cultural sciences by Apel, op. cit., pp. $31 \mathrm{ff} .:$ the interpretations of the historian are usually not strained by any responsibility for (justifiably) applying this understanding. In contrast to this, the interpretations of the natural scientist often carry such applicative responsibilities. In the laboratory, interpretation certainly is concerned with application, i.e. the production of measurement signs.

30. Habermas, op. cit., pp. 192-193.

31. Peirce, op. cit., pp. $307 \mathrm{ff}$.

32. Apel, op. cit., pF. $25 \mathrm{ff}$.

33. For a more sophisticated treatment of social and cognitive variables see for example Peter Weingart, Wissenproduktion und Soziale Struktur (Frankfurt, 1976).

34. Bourdieu, op. cit., p. 19.

35. It should be noted that what is proposed here is a quasi-economic model of the field and not of the scientist. With Bourdieu's approach the assumption is not that scientists are consciously motivated toward maximizing symbolic profit, but rather that accumulation and monopolization of symbolic capital are what is at stake in a social field like a scientific specialty. From what was said about credit as a social and cognitive capital in contrast to recognition and from the fact that the present theory is not a theory of motivation, the basic difference between the present approach and social studies of science which assume recognition to be the central motivation of scientists should be obvious.

36. Here Bourdieu is patently wrong when he asserts that scientists have an interest in disguising their self-interested strategies. An interest in "recognition," "scientific credit" or a high authority position is readily admitted in interviews with scientists. Such an interest could only appear threatening to the system if its presence implied a reduction in the objectivity, hardness, or quality of scientific results. As long as a high correlation is assumed to exist between competence and symbolic capital (as in the functionalist school), or an almost tautological relationship (as in Bourdieu), it is not clear why there should be such a coverup strategy. See Bourdieu, op. cit., p. 26.

37. The monograph of Latour and Woolger, op. cit., provides a rich variety of further examples which underline this point. The point can also be made by tracing the tactical moves present in scientific papers. See for instance Bruno Latour and Paolo Fabri, "La rhetorique du discours scientifique," Actes de la Recherche 13 (1977), pp. 81-95.

38. The term "agonistic" is meant to refer to a situation of generalized structural conflict which does not necessarily involve direct antagonism. See my "Producing and Reproducing Knowledge: Descriptive or Constructive?" Information sur les sciences sociales 16 (1977), pp. 669-696. The term "agonistic" as used here is taken from Bruno Latour. See for example Bruno Latour, "Accumulation and Circulation of Scientific Credit. A Model for Guiding a Comprehensive Sociology of Science," Proceedings of the First International Conference on Social Studies of Science, Vol. 1 (Cornell University, Ithaca, N.Y., 1976).

39. This concept holds whether the field is defined as a narrow socialty or a larger discipline. There are overlapping borders between disciplines, and fields are open systems with respect to their industrial and political environment.

40. In California during 1976-1977, energy was one of the most relevant issues in the larger environment. Research results have been equally "affected" by a generally 
increasing interest in biological quality, which provided another reason for supporting the chemical method mentioned above.

41. Parts of this and the following example have been used in: Karin D. Knorr, "Producing and Reproducing Knowledge: Descriptive or Constructive?" op. cit. The notion of idiosyncracy is elaborated in: Michel Serres, La Distribution (Paris, 1977), and used in a way similar to the present paper in: Latour and Woolgar, op. cit., ch. 6.

42. However, if the process is interrupted at any point in time by the observer, the "reasons" at work seem clearly identified. Distinctions between social, cognitive or institutional factors seem applicable.

43. One might also point out that the need to evaluate producers rather than products as stressed by Bourdieu derives from the idiosyncratic nature of the information generated. See Pierre Bourdieu, "La production de la croyance: Contribution a une economie des biens symboliques," op. cit.

44. Habermas' argument, although illustrated by actual behavior in the conduct of inquiry, aims at the conditions of instrumental action and its success. Work (especially labor, i.e. the production of exchange value in a capitalist system) presupposes and continually reproduces the social relationships which sustain it.

45. It should be emphasized once more that the point is not that scientific findings are not replicable, but rather, that producing a "good" paper means - except for rare cases during controversy - producing a distinctive (in the sense of different and excellent) paper, and that locally idiosyncratic constellations of equipment, natural source material, know-how, etc., promote distinctiveness. In the light of this, standardization of certain routine techniques over a variety of different local contexts might indicate the dominance or monopoly of a certain approach rather than the universal or international character of science. For an analysis of distinctiveness as aimed at in scientific papers see my "From Scenes to Scripts: on the Relationship between Research and Publication in Science," in a special issue on scientific discourse of Actes de la Recherche (Winter 1978).

46. Consequently, what is at stake in science as in economics is the exchange value and not the use value of products. In this sense, Storer's formulation that scientists exchange their products for recognition hits a point. Neither his conception of scientific communities nor of the exchange process are adequate, however. See Norman W. Storer, The Social System of Science (New York, 1966), and the criticism implied in my "Producing and Reproducing Knowledge: Descriptive or Constructive,"op. cit., p. 689.

47. The notion of analog reasoning has been expounded in my "Reasoning and Relativsm: A Constructivist Synthesis for Science," (Paper delivered at the Symposium on the Analysis of Scientific Discourse, San Diego, April 15-16, 1977), and in Latour and Woolgar, op. cit., ch. 3. The importance of metaphor (a form of analogical reasoning) in science was originally emphasized in: Max Black, Models and Metaphors (Ithaca, N.Y., 1962), and Mary Hesse, Models and Analogies in Science (Indiana, 1966).

48. Of course, what is considered satisfactory depends again on the resources of the scientist and the structure of the field. Technical and organizational difficulties are accepted and countered more readily if there is a high symbolic profit to be expected from the results.

49. The relationship between abstraction, comparability and the emergence of values was discussed by Baudrillard in his critique of Marxism. See Jean Baudrillard, Pour une critique de l'economie politique du signe (Paris, 1972).

50. There is another occurence of theory in the research process which is irrelevant here: as an object of study (cf. the case of the dilution theory), theory has the same status as other objects.

51. Not surprisingly, scientists themselves are often well aware of this role of theory in 
research: "From the point of view of the physicist, a theory of matter is a policy rather than a creed; its object is to connect or coordinate apparently diverse phenomena, and above all to suggest, stimulate and direct experiment". See Joseph John Thomson, The Corpuscular Theory of Matter (London, 1907), p. 10. Bachelard holds an equally relevant opinion: see Gaston Bachelard, Nouvel esprit scientifique (Paris, 1934), p. 11.

52. Habermas used a similar formulation to refer to the fact that the sciences lack the kind of theory which would permit them to reflect on "knowledge-constitutive" interest structures. See Habermas, op. cit., p. 315.

53. Unless, of course, one takes "technical control" in general as the pre-given end.

54. Two other connotations of instrumentality, control by success (not by feedback!) and dominance of instrumentation, prove much more adequate.

55. The generativity of the research process is of course related to the scientist's strategy of "distinguishing" him or herself as against the background of the not-yetaccepted literature of the field.

56. One might speculate that success works much better than truth as a mechanism of psychological motivation because of the constant reinforcement provided by cash outs (rewards!).

57. This is shown in: James G. March and Herbert A. Simon, Organizations (New York, 1966) as a general result referring to human decision making.

58. Bourdieu, "The Specifity of the Scientific Field and the Social Conditions of the Progress of Reason," op. cit.

59. The notion has been used recently by Francois Jacob, "Evolution and Tinkering," in Science 196 (1977), pp. 1161-1166. The notion of tinkering as invoked here is not to be confused with Kuhn's "puzzle solving" which mainly relates to the preestablished character of the solutions found in research in terms of the guiding paradigm. The concept of tinkering, in contrast, relates to the role of the above mentioned opportunities (such as idiosyncratic constellations of equipment, source materials, know-how, etc.) in orienting research production, and to the fact that the same problem when raised in different contexts will consequently not give rise to the same solution. Furthermore, the notion of tinkering in contrast to Kuhn's puzzle-solving must be embedded in a theory which locates the social aspects in the cognititive moves rather than adding them to the latter (see above) and which stresses the regulative force of the not-yet-accepted literature in a field rather than that of the accepted, "paradigmatic" knowledge: for it is mostly the not-yetaccepted literature which determines what is done in the laboratory, and against which new papers attempt to "distinguish" themselves.

60. According to van Fraassen, scientific realism ultimately derives from the question of how to explain the success of a theory if not by assuming the existence of the elements and mechanisms it postulates. As is well known, the argument has a long history in philosophy of science. For a presentation of scientific realism, see for example Wilfrid Sellars, Science, Perception and Reality (New York, 1962) and the above mentioned B. van Fraassen, "Wilfrid Sellars on Scientific Realism," Dialogue 5 (1975), pp. 606-616.

61. To paraphrase Dilthey, one could say that "the mind only understands what it has created." See Dilthey, op. cit., Volume 7, p. 148.

\section{Acknowledgment}

I am heavily indebted to the scientists at the observed institution who willingly served as informants and commentators on the data collected; to Bruno 
Latour for the many intense discussions we had and for his collaboration on some passages; to John Searle, Roger Krohn, Richard Ogar and Gerald Cole for their comments, suggestions, and editorial help, and to the Institute for Social Change, University of California Berkeley, which facilitated my research. 